\title{
BAROJA Y LA MODERNIDAD
}

Carmen M. ${ }^{\text {a Pujante Segura }}$

Universidad de Murcia

La hispanista italiana Giovanna Fiordaliso, profesora de literatura española en la Università della Tuscia (sita en la ciudad de Viterbo), regresa al estudio del escritor Pío Baroja, cuya obra en esta ocasión es observada y analizada desde el amplio ángulo de la modernidad, abrazando desde teoría de la novela hasta ideas alegóricas, pasando por la referencia a Gracián ${ }^{1}$. Sus casi trescientas páginas ven la luz en italiano para una editorial española en el año 2019, tres años después de haber emprendido y alentado, junto a la profesora Luisa Selvaggini, una primera incursión a través de un seminario en el que participaron otros hispanistas interesados en la obra barojiana y que ha quedado plasmado gracias a un volumen publicado en 2017 en Pisa.

A ese conocimiento de Baroja, alimentado con el intercambio, Fiordaliso aporta su indiscutible y veterano bagaje, curtido en el ancho campo de los géneros del yo (el autobiográfico y el ensayístico, principalmente), pero sobre todo en el del género narrativo. Este lo conoce bien, pues sus investigaciones han ido basculando entre el Siglo de Oro (con incursiones en autores como Salas Barbadillo o Céspedes y Meneses en cuanto epígonos de la picaresca, incursiones en las que se aprecia la estela de una de sus maestras, Giulia Poggi) y el último siglo (con estudios sobre José Manuel Caballero Bonald, Carmen Martín Gaite, Antonio Muñoz Molina, Rosa Montero, Monserrat Roig, Soledad Puértolas, etc.). G. Fiordaliso no desatiende la bibliografía existente en el hispanismo italiano en torno a P. Baroja (como la de Cangiotti de 1969 o la de Cessi Montalto de 1981), bibliografía cuya escasez dentro de la ispanistica, no obstante, contribuye a paliar y potenciar y entre la que ya reluce como destacada estudiosa. Pero no solo domina la narrativa moderna y contemporánea sino que tiene en consideración los imprescindibles estudios sobre este escritor español (como los Abad Nebot, Alberich, Alonso, Arbó, Arregui, Baeza, Basanta, etc.), algunos llevados a cabo por maestros relacionados con la revista

\footnotetext{
${ }^{1}$ Giovanna Fiordaliso, Baroja e la modernità. Gracián, spunti allegorici e teoria del romanzo, Vigo, Academia del Hispanismo (Publicaciones Académicas. Biblioteca de Escrituras Profanas, 65), 2019.
} 
Monteagudo: por supuesto, Mariano Baquero Goyanes, pero también Francisco Flores Arroyuelo o Gonzalo Sobejano.

Este estudio recientemente publicado se ha de valorar por varios motivos, en sí mismos acertados pero hoy en especial candentes, como es el de su enfoque desde la teoría sobre la novela. En ese terreno han aumentado recientemente las aproximaciones, como la de Luis Beltrán Almería en varios trabajos, como el incluido justamente en el volumen de conjunto sobre la teoría de la novela y el cuento de Baquero Goyanes. Pero también es oportuno por cuanto maneja una idea amplia de la modernidad, en tanto que concepción artística que va más allá de la caducidad temporal. Ello también contribuye a encajar el amplio sentido de la alegoría, todo lo cual le permite a este estudio trascender las coordenadas en las que inicialmente se centra, a saber, obras publicadas por Baroja en la década de los años 20. En su introducción (titulada «Fiere, caverne e labirinti», esto es, sobre ferias -de la vanidad-, cavernas y laberintos) condensa acertadamente su planteamiento o propuesta a partir del rescate por parte del propio Baroja de una idea iluminada en 1905 pero abandona hasta los años 20 :

Si ripresenterà nei romanzi che Baroja pubblica negli anni '20, quando ripropone la feria, insiema alla barraca e molte altre immagini ancora, in chiave però filosofica: è dunque a questo decennio che intendo dedicara la mia attenzione, in quanto epoca in cui l'autore mette a frutto una riflessione che parte da lontano, e che raggiunge finalmente una sua originalità trovando nella prosa allegorica di Gracián, e in particolare nel Criticón, direttamente ciatato in alcuni romanzi di questi anni, una soluzione alternativa a quanto scritto fino a questo momento. La sensualidad pervertida (1920), El laberinto de las sirenas (1923) e la trilogia Agonías de nuestro tiempo (1926), insieme a La nave de los locos, pubblicata nel 1925 e parte delle Memorias de un hombre de acción, sono opere a cui la critica ha riservato una scarsa attenzione e che rapprensetano invece una tessera fondamentale di quello sfaccettato mosaico che è la torrenziale scrittura di Baroja, e con essa la letteratura del primo Novecento, di cui è stato testimone e interprete. (2019: 15)

Tras esas páginas introductorias, se despliega el estudio a partir de tres secciones: «Vidas sombrías: gli albori della scrittura», «Le soglie della finzione» y «Gli anni» 20: la vuelta a Gracián». Así pues, la estudiosa afronta con arrojo el paso por terrenos movedizos como son las ramificaciones intrincadas de la escritura, los umbrales o pasajes de la ficción y los profusos años veinte en la literatura (cuando unos volvían su mirada a Góngora, mientras un Baroja maduro regresaba a Gracián). Todos esos flecos podrían explicar que los textos que ahora justamente decide estudiar Fiordaliso hayan quedado a la sombra respecto de otros escritores o incluso en el seno de la 
propia obra barojiana. Rescatándolos, releyéndolos, repasándolos, la estudiosa les da una nueva vida en la investigación y en la interpretación.

Esos enfoques no le impiden que mire hacia otros lados de la obra barojiana, como el del cuento, que también ha estudiado Fiordaliso. Y es que la autora se mueve con soltura entre conceptos de un cariz más teórico-críticos, consciente de dificultades como las que entrañan los géneros literarios. En consonancia con ello, tiene en cuenta los paratextos como el título, los retratos literarios, las escenas y los cuadros junto a las estampas, o las ideas metaliterarias o artísticas en general, sobre todo en su acercamiento a Vidas sombrias en la primera parte. Igualmente, tiene presente esa forma que parece incluir todo, la reescritura, los juegos y los espejos laberínticos, en especial en la segunda parte. Y en la tercera, a propósito de ese regreso de Baroja a la inspiración de Gracián, sobre todo con motivo de La nave de los locos, no olvida a Azorín ni la consideración de la alegoría y los espacios. Todo ello le lleva a concluir en un balance final con la postulación de un camino hacia un «nuovo romanzo», unos postulados para una nueva novela.

De lectura fluida y precisa, como ha de ser la de quien busca compartir o divulgar su conocimiento, a este trabajo bien se le podría augurar una «secuela» para engrosar los otros trabajos que Fiordaliso ya ha dado para el campo investigador en español, pues no es difícil vaticinar que no serán pocos los estudiosos interesados en esta nueva lectura de la obra barojiana. 